International Journal of Behavioral Research \& Psychology (IJBRP)

ISSN 2332-3000

\title{
Who is working at work?
}

Kathy Sexton-Radek

Editorial

C.BSM Suburban Pulmonary \& Sleep Associates/Elmhurst College, Illinois,USA

\section{*Corresponding Author:}

Kathy Sexton-Radek,

C.BSM, Suburban Pulmonary \& Sleep Associates/Elmhurst College,

Illinois,USA

E-mail:ksrsleep@aol.com

Received: July 16, 2014

Published: July 25, 2014

Citation: Kathy S R (2014) Who is working at work?. Int J Behav Res Psychol. 2(1e), 1. doi: http://dx.doi.org/10.19070/2332-3000-140002e

Copyright: Kathy S R $\mathbf{R}^{\circ} 2014$ This is an open-access article distributed under the terms of the Creative Commons Attribution License, which permits unrestricted use, distribution and reproduction in any medium, provided the original author and source are credited.

Recently in Chicago, the subway blue line train derailed off the track and up two flights of stairs at the O'Hare airport stop. The news accountings related that the driver of the train, a new employee of less than three months had recently worked a double shift and had accumulated other double shifts earlier that week. The incident is under investigation and it certainly called our attention to the devastation of sleep deprivation effects at the workplace. The National Transportation and Safety board recommends screening programs to identify drivers at high risk of sleep disturbances (and possibly including sleep disorders such as Obstructive Sleep Apnea) [1]. Some medical centers offer public announcements about sleep disturbances, education about sleep hygiene practices and treatments. To these efforts, Public Awareness is accentuated with media information online and through paper and media outlets about the effects of poor sleep on daytime functioning. While there are no Office of Health and Safety Association (OHSA) standards related to sleepiness at work, numerous public service announcements have been issued in terms of sleep related and fatigue issues and work safety. Finally, mandates such as the Residency sleep/work requirements have made strong impact on the reduction of errors and human costs related to poor/deprived sleep [1].

Despite the large and varied number of services to communicate the impact of poor sleep on daytime functioning such as work, accidents at the workplace related to sleepiness prevail. It has been reported that $29 \%$ of workers reported feeling sleepy at work $[1,2]$. This sleepiness has been related to work-related accidentsand work performance decrements. It is estimated that some $17 \%$ of American workers report feeling sleepy and reduce their personal work performance accordingly $[1,2,3]$. Highly sleepy workers are estimated to be 70 times more likely to be involved in a work related accident [1].

Many efforts to address sleepiness and poor sleep quality amongst workers are most strongly and comprehensively conducted by the medical community [2,4]; while the impact of poor sleep at the workplace is at the awareness, descriptive information level. With the mounting economic and personal costs of poor work performance/attrition, absenteeism, and accidents at the workplace related to poor sleep, some accentuation is in order. Perhaps efforts may be increased at the governance level and the individual company mission statements. A consideration of standard number of hours for operating and driving heavy equipment such as the medical residency requirements may be helpful [4].That is, careful monitoring, universally of work schedule and overtime to deter decrements in performance secondary to sleep loss may be in order [5]. Perhaps sleep fitness tests where workers demonstrate at their annual physical a sufficient vigilance and concentration level to continue to complete their work tasks may be considered with rewards for stable performance and education/treatment if poor performance. At the company level, rest areas, information about sleep hygiene and educational materials and workshops about the sleep hygiene may be beneficial. Mission statements that espouse the value and loyalty of the worker could be expanded to include their physical health that includes their sleep health as regarded. Practical, straight forward efforts that may relate to some of the consideration could be employed with moderate effort [6].

Currently the American Association for Sleep Medicine (AASM) is formulating a task force to the National Transportation \& Safety Association as well as some other major organizations in an effort to address the important issues of sleepiness at the workplace.The leadership modeled by AASM in this important issue will likely to provide strong understanding and directions for workable solutions to the difficult area of sleepy workers. These considerations and efforts, together, will hopefully address the issue of sleepiness/poor sleep quality in workers so that they can work at work $[1,6]$

\section{References}

[1] National Sleep Foundation. Sleep In America Poll 2012. www.nationalsleepfoundation.org

[2] Mitler M.M, Carskadon M, Czeisler C, Dement W.C, Dinges D.F, et al. (1988). Castastrophes, Sleep and Public Policy: Consensus Report. Sleep 11(1):100-109.

[3] Akerstedt T, Fredlund P, Billberg M, Jansson B (2002) A prospective study of fatal occupational accidents---relationship to sleeping difficulties and occupational factors. Journal of Sleep Research 11(1):69-71.

[4] Lindberg E, Carter N, Gislason T, Janson C (2001) Role of snoring and daytime sleepiness in occupational accidents.American Journal of Critical Care Medicine 164(11):2031-5.

[5] Lockley St. W, Cronin J.W, Evans E.E, Cade B.E, Lee C.J (2004) Effect of Reducing Interns' Weekly Work Hours on Sleep and Attentional Failures. New England Journal of Medicine 351:1829-1837.

[6] Sexton-Radek, K. Graci G (2012) Combating Your Sleep Disturbance. New York: Pergamon Press. 